\title{
The Roles of Price Points and Menu Costs in Price Rigidity*
}

Edward S. Knotek II

Federal Reserve Bank of Kansas City

December 27, 2010

\begin{abstract}
Macroeconomic models often generate nominal price rigidity via menu costs. This paper provides empirical evidence that treating menu costs as a structural explanation for sticky prices may be spurious. Using supermarket scanner data, I note two empirical facts: (1) price points, embodied in nine-ending prices, account for more than 60 percent of prices; (2) at the conclusion of sales, post-sale prices return to their pre-sale levels nearly 90 percent of the time. I construct a model that nests roles for menu costs and price points and estimate model variants via simulated method of moments. Excluding the two facts yields a statistically and economically significant role for menu costs in generating price rigidity. Incorporating the two facts yields an incentive to set nine-ending prices two orders of magnitude larger than the menu costs in this model. In this setting, the price point model can match the two stylized facts, but menu costs are effectively irrelevant as a source of price rigidity. The choice of a mechanism for price rigidity matters for aggregate dynamics.
\end{abstract}

Keywords: price rigidity; menu costs; price points; nine-ending prices; simulated method of moments

JEL codes: E31, L11, D40, C15, M31

\footnotetext{
* I thank Yuriy Gorodnichenko, Chris House, Stephen Terry, my discussant Ben Malin, and seminar and conference participants at the Federal Reserve Bank of Kansas City, Federal Reserve System Macro Meeting, Federal Reserve Bank of San Francisco, University of Oklahoma, Midwest Macro, and the Society for Computational Economics Conference on Computing in Economics and Finance for comments and suggestions; Kathleen Navin for assistance with the Dominick's data; and the James M. Kilts Center at the University of Chicago Booth School of Business for providing public access to the Dominick's Finer Foods scanner database used in this project. The views expressed herein are solely those of the author and do not necessarily reflect the views of the Federal Reserve Bank of Kansas City or the Federal Reserve System. Contact information: Economic Research Department, Federal Reserve Bank of Kansas City, 1 Memorial Drive, Kansas City, MO 64198. Tel.: (816) 881-2596. Fax: (816) 881-2199. Email: edward.knotek@kc.frb.org.
} 
Sticky prices are an integral component of most macroeconomic models that generate considerable periods of monetary nonneutrality. Understanding the mechanisms that produce price rigidity is therefore an important task for building proper micro foundations of these macro models. Following a long tradition, the most commonly modeled structural impediments to price adjustment are menu costs - the costs associated with literally changing the price of an item. In this paper, I provide empirical evidence that menu costs per se are largely irrelevant as a source of price rigidity.

Using scanner price data from Dominick's Finer Foods, a Chicago-area supermarket chain, I document and discuss two stylized facts. First, more than 60 percent of Dominick's prices end in the digit nine - a highly prominent price point. Second, at the conclusion of sales (i.e., temporary price mark-downs), post-sale prices return to their pre-sale levels nearly 90 percent of the time.

I set out a simple menu cost model and show that this class of models is inconsistent with these facts. The inability to match the former fact is partly mechanical, since the relevant state in menu cost models is usually the firm's real price instead of its nominal price. Nevertheless, retaining nominal prices would result in approximately 10 percent of prices ending in nine- the probability of drawing this digit by chance. The inability to match the second fact is more problematic. By design, menu cost models are forward looking. If the firm pays the menu cost and adjusts its price, the new price will incorporate all relevant information. This implies that, under even extremely low rates of inflation similar to what Dominick's experienced, post-sale prices will rarely if ever return to their pre-sale levels.

I then consider an extension of the menu cost model that allows for the possibility that a firm may have an incentive to use price points. This model yields several noteworthy effects. 
First, it can generate an overreliance on prices that end in the digit nine. Second, the use of these price points can result in both price rigidity — since the firm may be reluctant to change its price away from a nine ending — and relatively large price changes when it does adjust even in response to small changes in its costs—-since it may jump to nearby nine-ending prices. Third, price points also naturally create an incentive for a firm to return post-sale prices precisely back to their pre-sale levels.

I estimate these models on the Dominick's data via simulated method of moments. Excluding the above facts and price points, I show that one would estimate a statistically and economically significant menu cost to match commonly cited moments related to price rigidity. However, the model cannot match the two above facts.

I next turn to the model that allows for price points and menu costs. Incorporating the two stylized facts into the estimation along with the other price rigidity moments yields an incentive to set price points roughly two orders of magnitude larger than the menu costs in this model. In this setting, the price point model can match the two stylized facts, but menu costs are effectively too small to generate substantial price rigidity. These results suggest that relying on menu costs as a structural explanation for price rigidity — which is arguably their most attractive feature in macro models featuring state-dependent pricing — may be spurious.

Extending the model to illustrate its implied aggregate behavior, I show that the choice of a mechanism for price rigidity matters for macro dynamics. Using the estimated parameters, the price point model generates movements in output distinct from those of the simple menu cost model. In particular, money is essentially neutral in the aggregated price point model. This result weakens the case for using sticky prices as a key source of monetary nonneutrality. 
The marketing and retailing literatures have long recognized the importance of price points and price endings, especially the digit nine. With the notable exceptions of U.S. empirical work by Kashyap (1995), Blinder et al. (1998), and Levy et al. (forthcoming), the sticky price literature has largely avoided this issue, instead relying primarily on menu costs to generate price rigidity in state-dependent pricing models. This paper integrates price points and menu costs into a single framework and estimates the parameters of the model.

This paper also contributes to the sticky price literature and the debate about the importance of sales. Klenow and Kryvtsov (2008), Nakamura and Steinsson (2008), and Kehoe and Midrigan (2008) show that including or excluding sales has a dramatic impact on estimated average durations between price changes, which in turn affects the results of macro models calibrated to one or the other duration. The fact that most sales are "undone" - in that the firm's post-sale price returns to its pre-sale level-lends some support to the view that sales should be treated as special or as a nuisance to abstract from in macro models. Instead, I argue that the behavior of prices around sales is as an important test of structural price-setting models. Ultimately, this behavior is more supportive of price point models than canonical menu costs. An additional drawback of menu cost models is their inability to generate small price changes: the presence of a menu cost that is sufficiently large to deter too-frequent adjustment also prevents many small price changes. As noted by Midrigan (forthcoming), while the average absolute size of price changes tends to be relatively large in the empirical data, there are also many small changes in absolute value. While not a part of the estimation, the price point model closely matches the frequency of very small price changes (less than 2.5 percent and less than 1 percent in absolute value) in the Dominick's data. 
Price points can help rationalize the inertia that Eichenbaum et al. (forthcoming) find in reference prices-i.e., the most commonly used prices within a quarter. Intuitively, price points help to channel firms' prices to certain nominal levels. In this framework, there is no longer a need to assume that firms are restricted to choosing from a small set of prices prescribed by a "price plan" that is costly to adjust, as in Eichenbaum et al. (forthcoming).

Section I discusses the Dominick's data used in this paper and the stylized facts of interest. Section II presents a model that allows a role for price points and menu costs in a firm's price-setting problem, and Section III sets out the estimation strategy. Parameter estimates are presented in Section IV. Section V discusses the results in the context of the literature. Section VI considers the aggregate implications of the models, and Section VII concludes.

\section{Stylized Facts on Price Endings and Sales in the Dominick's Data}

The data for this paper come from the scanner database of prices for Dominick's Finer Foods, a Chicago-area supermarket chain. The database contains more than 3,500 items with UPC labels. The data are available at a weekly frequency, beginning in September 1989 and running for 400 weeks through May 1997. The entire dataset contains nearly 99 million observations, and the vast majority of items are relatively inexpensive, as shown in Figure 1. For computational feasibility when working with the estimation below, I restrict attention to prices in the range of $\$ 0.50$ to $\$ 3.00$, capturing 74.3 percent (about 74 million) of the observations in the dataset.

This paper focuses on two facts from the Dominick's data. First, prices ending in the digit nine dominate the dataset. Figure 2 shows that 62.2 percent of prices have a nine in the final cents digit, far from the 10 percent that would occur if price endings were uniformly 
distributed. In addition, price endings are correlated with measures typically of interest in the price rigidity literature. For instance, the unconditional frequency of price changes is 25.0 percent in the Dominick's data. Conditional on the last period's price $\left(p_{t-1}\right)$ ending in the digit nine, the frequency of price changes is 21.5 percent. If $p_{t-1}$ did not end in the digit nine, the frequency of price adjustment is 30.5 percent. $^{1}$

The second fact of interest concerns the behavior of prices around sales. Sales, or temporary price markdowns, feature prominently in the Dominick's data. ${ }^{2}$ Conditional on a good not being on sale in the previous period, the probability of starting a sale is nearly twice the probability of a non-sale price change (10.0 percent versus 5.6 percent). Since sales involve two changes - an initial decrease and a subsequent increase - they comprise the majority of all price adjustments in the dataset.

In the Dominick's data, prices exhibit memory around sales: at the conclusion of a sale, they return precisely to their level from immediately prior to the sale 89.0 percent of the time. Such a finding is not unique to supermarkets. Using data underlying computation of the U.S. consumer price index, Klenow and Kryvtsov (2008) and Nakamura and Steinsson (2008) find broadly similar patterns.

The frequency with which post-sale prices return to their pre-sale levels differs depending on the pre-sale price ending. As Figure 3 shows, the unconditional frequency of post-sale prices not returning to their pre-sale levels is 11.0 percent. However, conditional on the last pre-sale price ending in the digit nine, only 6.1 percent of post-sale prices differ from their pre-sale level;

\footnotetext{
${ }^{1}$ Levy et al. (forthcoming) present more detailed empirical analysis relating to nine endings in the Dominick's data. Studies of micro data underlying consumer price indices from the Eurosystem's Inflation Persistence Network also find a statistically significant role for "attractive prices"-i.e., price points, including nine endings—in regressions on the frequency of price changes; see Dhyne et al. (2006) for a review of this evidence.

${ }^{2}$ The Dominick's data contain a variable indicating whether a good was on sale for the week or not, but the sale codes were not applied in a consistent manner and thus are not used in this analysis. For consistency and comparability between the Dominick's data and the model simulations below, I construct a sales filter to determine the start and end dates of sales. The Appendix provides details on the sales filter.
} 
that is, in this case Dominick's is more likely to return the price of the good to its old level than normal. By contrast, conditional on the last pre-sale price ending in a digit other than nine, postsale prices differ from their pre-sale level 22.4 percent of the time. ${ }^{3}$ These statistics suggest that Dominick's treats prices that end with the digit nine as price points with special properties.

\section{A Model of Price Points and Menu Costs}

The model I consider has the following features. Within a given period, the firm determines the nominal price $p$ it would like to charge for an item. As in the canonical Dixit-Stiglitz framework, in a frictionless world the firm would always wish to set $p$ equal to a desired markup $\mu$ over its nominal marginal cost, denoted $m c$.

The firm potentially faces two consequential frictions. The first friction allows for the possibility that price changes are costly: there is a menu cost to changing a price from its previous level, due to the physical costs of literally adjusting the price of an item. Each price change reduces profits by a constant, fixed amount $\Phi \geq 0 .{ }^{4}$ Such nonconvex adjustment costs follow in a long tradition in the sticky price literature.

The second friction comes from the possibility that price points may factor into the firm's pricing problem. The marketing and retailing literatures have proposed a number of mechanisms through which price points, especially nine-ending prices, may benefit sellers. Typically, these mechanisms involve a departure from pure rationality: consumers are assumed to truncate or underestimate price points - due to rational inattention, limited recall, or the desire to simplify

\footnotetext{
${ }^{3}$ Of those 22.4 percent of prices, greater than 50 percent go to a nine-ending price.

${ }^{4}$ This notably differs from the framework of Midrigan (forthcoming), where there are economies of scale in changing prices; and Midrigan and Kehoe (2008), where there are different menu costs associated with regular and temporary price changes. I discuss these points in more detail below.
} 
price comparisons across items by mentally coding using left-to-right, digit-by-digit comparisons until the first difference is noted—or they associate price points with sales. ${ }^{5}$

As a result, price points can result in kinks (or discontinuities) in the demand curve that are present in the firm's profit function as well—with the effect that the price points are local profit maxima. For example, suppose consumers truncate the final cents' digit. This would transform an otherwise linear (log-linear, etc.) demand curve into a step function. Since demand would be identical for a price of $\$ 1.50$ and $\$ 1.59$, the firm would earn higher revenues and profits from setting the $\$ 1.59$ price. Moving from $\$ 1.59$ to $\$ 1.60$ would result in a disproportionate decline in demand and, under general circumstances, a lower level of profits. For the sake of tractability and estimation feasibility, and to remain agnostic on the precise mechanism at play, this paper posits that firms may benefit directly from the use of price points ending in the digit nine via $\kappa \geq 0$, which captures the profit implications of setting a price point.

The above concepts can be parsimoniously represented as affecting a firm's profits for good $i$ at time $t$ through the use of a quadratic loss function

$$
\Pi(p, m c, \mu)=\chi-\left(\frac{p}{m c}-\mu\right)^{2}+\kappa[I(p \in\{\text { price points }\})] .
$$

In the absence of any frictions ( $\kappa=0$ and $\Phi=0$ ), the firm would set its price $p$ equal to its desired markup over marginal cost, earning some level of profits $\chi$.

In the presence of frictions, deviations of the actual price $p$ from its frictionless optimal level (equal to $m c \times \mu$ ) entail a reduction in profits via the curvature of the profit function. These deviations can arise in the presence of a menu cost $\Phi>0$ that must be paid when changing the price of good $i$, since in this case the firm may not always pay the menu cost in order to keep its

\footnotetext{
${ }^{5}$ Among others, Georgeoff (1970) and Schindler and Kirby (1997) discuss truncation and underestimation, Brenner and Brenner (1982) and Thomas and Morwitz (2005) discuss mental coding, and Schindler (1991) discusses the association with sales prices.
} 
price at its desired markup over marginal cost. They can also arise when $\kappa>0$, since in this case a firm's profits will depend on whether $p$ is a nine-ending price point — and hence the indicator variable $I(p \in\{$ price points $\})=1$-or not. As a result, under some circumstances profits may be higher from setting a nine-ending price point than from setting $p=m c \times \mu$.

Within a given period $t$, the firm observes its contemporaneous marginal cost $m c$ and desired markup $\mu$ - both of which evolve exogenously to the firm — and decides whether to keep its price $p$ or change it. The firm discounts the future at rate $\beta$. The value to the firm of keeping its price $p$ is

$$
V^{K}(p, m c, \mu)=\Pi(p, m c, \mu)+\beta E V\left(p, m c^{\prime}, \mu^{\prime}\right)
$$

with $E$ the expectations operator over future unknown values of marginal costs and desired markups. The value to the firm of changing its price is

$$
V^{C}(p, m c, \mu)=\max _{\tilde{p}} \Pi(\tilde{p}, m c, \mu)-\Phi+\beta E V\left(\tilde{p}, m c^{\prime}, \mu^{\prime}\right)
$$

which captures the menu cost $\Phi$ needed to change the price to $\tilde{p}$. Thus, the firm decides whether to change its price or not based on

$$
V(p, m c, \mu)=\max \left\{V^{K}(p, m c, \mu), V^{C}(p, m c, \mu)\right\}
$$

Intuitively, menu costs generate price rigidity by creating a range of inaction around the most recently set price. In response to small enough shocks, a firm facing a menu cost will wish to maintain the previous price. Once the shocks push the firm outside of this range, it will pay the menu cost and select a new price. By contrast, price points create incentives for the firm to select from a set of prices (e.g., those with nine-endings). This will cause prices from this set to be used disproportionately. In addition, price rigidity will depend on the characteristics of the current price itself (i.e., situational price rigidity). If the current price is a price point, this again 
generates a range of inaction in response to small enough shocks and hence price rigidity. But if the current price is not a price point, these prices may appear more flexible.

\section{Calibration and Estimation Strategy}

Central to this paper are the sizes of the menu cost, $\Phi$, and the price point effect, $\kappa$, in the firm's profits. Estimating these parameters requires calibrating other parameters where possible and specifying the exogenous processes for marginal costs $m c$ and markups $\mu$.

The data in the Dominick's database are weekly, which is the relevant timeframe for the firm's decisions. As such, the discount rate is $\beta=0.96^{1 / 52}$, as in Kehoe and Midrigan (2008).

Without loss of generality, $\chi$ is normalized to ensure the value function is not near zero.

In keeping with the spirit of the sticky price literature, nominal marginal costs for a good have two components: a "price" component $P$ and a "real" component $c$, such that $m c=P \times c .{ }^{6}$ The price component evolves according to

$$
\ln P=\bar{\pi}+\ln P_{-1}+\zeta
$$

with $\zeta$ an i.i.d. normal random variable with mean zero and standard deviation $\sigma_{\zeta}$. Converting monthly inflation for the non-seasonally adjusted consumer price index for food and beverages to weekly inflation over the Dominick's sample period yields $\bar{\pi}=5.7 \times 10^{-4}$ and $\sigma_{\zeta}=1.7 \times 10^{-3}$.

The real component of marginal costs evolves according to

$$
\ln c=\ln c_{-1}+\varepsilon
$$

\footnotetext{
${ }^{6}$ That is, sticky price models typically use the firm's real price $p / P$ as the relevant state. Since profits in equation (1) depend on $p / m c$, this interpretation of nominal costs is equivalent to having $(p / P) / c$ in the profit function. The component $c$ then captures the idiosyncratic productivity shocks that have become standard in state-dependent pricing models based on menu costs; see, e.g., Golosov and Lucas (2007).
} 
As in Gertler and Leahy (2008), the shock has two components: $\varepsilon=\gamma \times \eta$. The random variable $\gamma$ governs the arrival of cost shocks, with $\operatorname{Pr}(\gamma=1)=\lambda$ and $\operatorname{Pr}(\gamma=0)=1-\lambda$. The random variable $\eta$ determines their size, with $\eta$ distributed uniformly on $[-\theta, \theta]$. Marginal cost is not well-measured in the Dominick's data and cannot be used to inform these parameters (see, e.g., Peltzman 2000).

Taking the model to the Dominick's data requires a prominent role for sales. While various theories have been proposed to explain sales, this paper models sales as arising in response to time-variation in the firm's exogenous desired markup $\mu$, which follows

$$
\mu=\bar{\mu}-\xi
$$

In a New Keynesian framework using Dixit-Stiglitz preferences, exogenous time-variation in the firm's desired markup could arise for instance through time-variation in demand elasticities. Based on the median markup of non-sale prices over average acquisition cost—which can be inferred from the measure of gross profit margins in the Dominick's dataset, and which I assume proxies for marginal cost in steady state-I calibrate the steady-state desired markup $\bar{\mu}$ to 1.42.

The random variable $\xi$ captures the desired sales state. If $\xi=0$, the firm wishes to set its price equal to its steady-state markup over marginal cost. If $\xi>0$, the potential for a sale occurs since the firm then wishes to set a lower markup and hence a lower price. The sales state is given by $\xi \in\left\{0, \xi_{s}, \xi_{b}\right\}$, which affords the opportunity for "big" and "small" sales $\left(\xi_{b}>\xi_{s}>0\right)$. The sales state follows a Markov process with transition matrix,

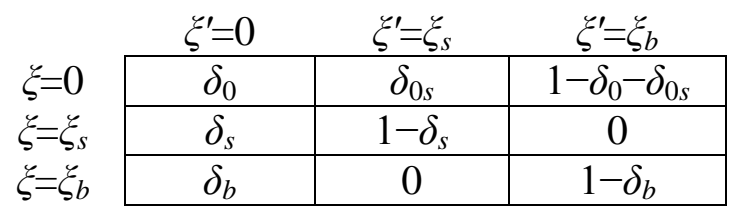

which rules out the possibility of sale-to-sale transitions. 
Thus, the model has ten parameters to estimate: (1) the sensitivity of profits to nineending price points, $\kappa$; (2) the menu cost, $\Phi$; (3) the probability of a marginal cost shock, $\lambda$; (4) the support of the marginal cost shocks, $\theta ;(5-6)$ the "big" and "small" sales states, $\xi_{b}$ and $\xi_{s}$, respectively; and (7-10) four parameters from the transition matrix, $\delta_{0}, \delta_{0 s}, \delta_{s}$, and $\delta_{b}$. I reduce the computational burden slightly by using two moments from the Dominick's data to inform $\delta_{0 s}$ and $\delta_{b}$. First, approximately 60 percent of sales are smaller than average, implying $\delta_{0 s}=0.6\left(1-\delta_{0}\right)$. Second, the average duration of a "big" sale is approximately 70 percent of the average duration of a "small" sale, implying $\delta_{b}=1.4 \delta_{s}$. This leaves eight parameters for estimation.

The model is estimated via simulated method of moments (SMM). Let $Z$ denote the vector of parameters to be estimated: $Z=\left[\kappa, \Phi, \lambda, \theta, \xi_{b}, \xi_{s}, \delta_{0}, \delta_{s}\right]$. The estimates $\hat{Z}$ minimize the weighted difference between a vector of estimated moments from the Dominick's data, $\hat{\psi}$, and a vector of moments produced via model panel simulations using parameters $Z, \tilde{\psi}(Z)$ :

$$
\hat{Z}=\underset{Z}{\arg \min }\left[\hat{\psi}-\frac{1}{S} \sum_{s=1}^{S} \tilde{\psi}_{s}(Z)\right]^{\prime} \Omega\left[\hat{\psi}-\frac{1}{S} \sum_{s=1}^{S} \tilde{\psi}_{s}(Z)\right],
$$

where $S=50$ is the number of replications of the simulated panel dataset over $I=50$ items and $T=81$ time periods, which is the average number of observed weeks per item in the Dominick's data. The positive definite weighting matrix $\Omega$ is the inverted bootstrapped variance-covariance matrix for the moments estimated from the Dominick's data. 


\section{Estimation Results}

I estimate two variants of the model. The first is a typical menu cost model omitting price points, in line with the sticky price literature. Next, I consider the complete model, estimating both the role of price points and menu costs. While the former exercise finds a significant statistical and economic role for menu costs, the latter exercise shows that menu costs are essentially irrelevant as a source of price rigidity after incorporating a role for price points into the analysis. These results are robust to several variations in the moments used in the estimation.

I select moments to identify the model's parameters based on common moments in the sticky price literature reflecting information on the frequency of price changes, their size, and the standard deviation of their size, along with moments related to sales behavior. I consider: (1) the frequency of non-sale price changes; (2) the average absolute size of non-sale price changes; (3) the standard deviation of the size of non-sale price changes; (4) the frequency of beginning a sale, conditional on not having a sale in the previous period; (5) the frequency of ending a sale, conditional on a sale in the previous period; (6) the average size of price changes associated with the start of sales; and (7) the standard deviation of the size of price changes associated with the start of sales. The final two moments are the facts from Section I: (8) the percentage of prices that end in the digit nine; and (9) the frequency with which post-sale prices differ from their presale levels. Column (a) in Table 1 provides estimates from the Dominick's data. 


\section{$\underline{\text { A Typical Menu Cost Model }}$}

To estimate the model with only menu costs (i.e., constrained estimation with $\kappa=0$ ), I discretize the actual markup state, $p / m c$, in 0.1 percent intervals over the relevant regions and constrain actions to this grid. ${ }^{7}$ With the nine-ending price point effect $\kappa$ set to zero by assumption, this leaves the menu cost $\Phi$ and six other parameters related to the frequency and size of the shocks in the model. Consequently, the model is just-identified with the first seven moments listed above.

Column (b) in Table 1 provides the parameter estimates and the resulting moments for the model with only menu costs. ${ }^{8}$ As the bottom panel shows, the model closely matches the data at the estimated parameters. The point estimate of the menu cost for this case is $2.51 \times 10^{-3}$, with a 90 -percent confidence interval computed to be from $2.18 \times 10^{-3}$ to $2.91 \times 10^{-3}$. Cost shocks arrive $(\lambda)$ in approximately 5.9 percent of periods, and the maximum absolute size of a cost shock $(\theta)$ is 9.8 percent, similar to the calibrations in Kehoe and Midrigan (2008).

Unlike in Kehoe and Midrigan (2008), matching the large standard deviation of the size of sale-related price changes requires allowing for multiple sales states. Thus, the big sale estimate $\left(\xi_{b}\right)$ implies a desired markup of 0.90 , while the desired markup during an estimated small sale $\left(\xi_{s}\right)$ is 1.32 . These numbers are consistent with large sales being "loss leaders" that are more transient than other sales.

The final two parameters relate to the transition matrix that governs the evolution of desired markups in Section III. The estimate of $\delta_{0}$ implies a 10 percent probability that the

\footnotetext{
${ }^{7}$ By the assumptions of the previous section, the other relevant state variable, $\mu$, can take on three values in each of the model variants: $\mu \in\left\{\bar{\mu}, \bar{\mu}-\xi_{s}, \bar{\mu}-\xi_{b}\right\}$.

${ }^{8}$ The 90 -percent confidence intervals reported in the table were constructed by re-estimating each model 100 times using different underlying draws for the shock processes. In this way, I account for variability arising from the selected set of random draws in the estimation procedure.
} 
desired markup will switch from its steady-state level to a lower, sale level in any given period. The estimate of $\delta_{s}$ implies that, conditional on the desired markup being $\mu=\bar{\mu}-\xi_{s}=1.32$, the desired markup will stay at that level in the next period with a two-thirds probability.

Interpreting the size of the menu cost is complicated by the fact that the simple loss function in equation (1) does not have a role for revenues or profits per se, since these are often compared with menu costs as in Levy et al. (1997) or Dutta et al. (1999). Column (b) in Table 2 presents an alternative interpretation: it computes the percent deviation between the actual markup, $p / m c$, and the steady-state desired markup, $\bar{\mu}$, that is equivalent to the estimated menu cost. For this model variant, paying the menu cost has the same contemporaneous negative effect on profits as allowing the actual markup to differ from the desired markup by 3.46 percent for one period. While not directly translatable to a dynamic setting, this estimate nevertheless implies that for "small" shocks to marginal cost there is an incentive for the firm to not necessarily pay the menu cost and change its price.

While the menu cost model can match the moments used in the estimation, it is incapable of matching the two facts set out in Section I: more than 60 percent of prices end in the digit nine, and post-sale prices return to their pre-sale levels nearly 90 percent of the time. As the gray shaded boxes show, the menu cost model would produce nine-ending prices 10 percent of the time - the probability of drawing this digit by chance. ${ }^{9}$

The inability to match the second fact is because of the forward-looking nature of menu cost models. If the firm decides to pay the fixed cost and adjust its price, the new price it sets will incorporate all relevant information since its last change. This implies that, under even

\footnotetext{
${ }^{9}$ Since $p / m c$ is the relevant state in this model and essentially all menu cost models, the notion of a nominal price is somewhat arbitrary and clearly not constrained to the traditional grid of prices, $\$ 1.00, \$ 1.01, \$ 1.02$, etc. This figure is found by rounding to two digits.
} 
extremely low rates of inflation similar to what Dominick's experienced, post-sale prices will rarely exhibit memory and return to their pre-sale levels, a pattern clearly illustrated in Figure 4. As the table shows, the menu cost model would predict that post-sale prices differ from their presale levels more than 90 percent of the time; the Dominick's data put this figure at 11 percent. Discretizing the state variables of the menu cost model in successively finer increments would push this moment arbitrarily close to 100 percent, though it would also render impractical the estimation due to time considerations. ${ }^{10}$

\section{$\underline{\text { Price Points and Menu Costs }}$}

I next consider the unconstrained estimation of the model by allowing a role for price points and menu costs. This estimation requires keeping track of nominal prices as a state, due to the indicator function $I(p \in\{$ price points $\})$ in equation (1). It also requires that prices be feasible under the monetary denominations. ${ }^{11}$ To this end, I discretize the nominal price $p$ and nominal marginal cost $m c$ states in one cent increments. Because the time required to solve, simulate, and estimate the model increases exponentially with the number of nodes in each state, I restrict attention to nominal prices in the range of $\$ 0.50$ to $\$ 3.00$ inclusive, which comprises the vast majority of the Dominick's data. Given this assumption and the values of the markup process, the bounds of the marginal cost process are endogenized. By adding another parameter ( $\kappa)$ to be estimated, I need at least one more moment; I add the two stylized facts set out above, then consider robustness below.

\footnotetext{
${ }^{10}$ The state space of the model was finely discretized to conform to standard practice in menu cost models. Conversely, requiring this model to use whole cent nominal price increments would produce a higher incidence of memory around sale prices, but the model would still not be able to match this particular moment.

${ }^{11}$ This rules out pricing in fractions of a cent, or pricing patterns such as two for $\$ 0.99$. Less than $1 \%$ of prices in the Dominick's database violate this assumption.
} 
Column (c) in Table 1 presents the results. In general, the model continues to be largely consistent with the moments commonly associated with the sticky price literature, but it is also now consistent with the two facts from Section I. The estimated nine-ending price point effect is $5.30 \times 10^{-4}$, with a 90 -percent confidence interval computed to be from $5.19 \times 10^{-4}$ to $5.65 \times 10^{-4}$. Thus, the estimation rejects the nested menu-cost-only specification for the larger set of moments. The estimate of the menu cost falls to $1.78 \times 10^{-6}$, with 90 -percent confidence interval $3.5 \times 10^{-7}$ to $1.12 \times 10^{-5}$. That is, the estimated nine-ending price point effect is roughly two orders of magnitude greater than the estimated menu cost in this model.

Even though the menu cost is statistically estimated to be greater than zero, it is effectively irrelevant as a source of price rigidity. For instance, setting the menu cost $\Phi$ to zero and keeping the other estimated parameters has a trivial effect: to two decimal places, the resulting moments are unchanged. Furthermore, as column (c) shows in Table 2, paying the menu cost now has the same contemporaneous negative effect on profits as allowing the actual markup to differ from the desired markup by a mere 0.09 percent. This implies that, by itself, virtually any shock to marginal costs would be big enough to justify a price change based on menu costs alone. By contrast, the price point effect is equivalent to a 1.6 percent difference between actual and desired markups. This friction is now a much bigger impediment to price changes than menu costs.

In terms of other parameters, the estimated arrival rate of cost shocks falls to 2.2 percent from 5.9 percent in the menu cost model. In spite of this, the frequency of non-sale price changes remains at 6 percent, in line with the Dominick's data. Implicitly, this means that some "sales"-i.e., price changes in response to desired markup shocks-may last longer than the sales window and instead be classified as non-sale price changes, and that some non-sale price 
changes are caused by drift in the price component of marginal cost. Indeed, sales are slightly more likely to occur under this case than under the menu-cost-only model, as implied by the lower estimate of $\delta_{0}$. Regardless, this is not necessarily a drawback to this model, since the Dominick's data also contain "sales" that last longer than the window used in the sales filter and therefore appear as non-sale price changes. While the sizes of the big and small sales states are comparable, the absolute size of cost shocks is slightly smaller than in the menu-cost-only case as well, at 8.3 percent.

\section{$\underline{\text { Robustness to Moment Selection }}$}

These results are robust to the exact moment chosen in addition to the more common sticky price moments. Since the model is now overidentified, I re-estimate the parameters by excluding one of the two added moments. Column (d) presents results from excluding the preversus post-sale pricing moment. As the table indicates, the parameter estimates and resultant moments are only trivially affected. The model continues to produce an extremely high percentage of post-sale prices that return to their pre-sale levels, even though this is not explicitly part of the criterion function used in the estimation procedure any longer.

Column (e) omits the "nines" moment from the estimation. Doing so produces a considerably larger estimate for the price point effect $\kappa$ than in columns (c) and (d). ${ }^{12}$ This results in a greater reliance on nine-ending prices in the simulations (91 percent) than what we see in the data (62 percent), since the larger estimate of $\kappa$ provides price setters in this estimation greater incentives to set these prices. By contrast, the estimate of the menu cost $\Phi$ is little

\footnotetext{
${ }^{12}$ Because the 90-percent confidence intervals were constructed using different draws for the shock processes, there is no guarantee that the original parameter estimates will fall within a given 90 -percent confidence interval — as is the case with the $\kappa$ estimate here.
} 
changed. As a result, the nine-ending price point effect is an even greater barrier to action than the menu cost, as indicated by column (e) in Table 2.

\section{$\underline{\text { Ability to Match Additional Moments }}$}

Beyond robustness exercises, it is also possible to consider how well the model matches moments not used in the estimation. Table 3 presents additional moments of interest in the Dominick's data in column (a). Columns (b) through (e) give the results from model simulations using the estimated parameters from Table 1.

Midrigan (forthcoming) notes that the Dominick's data contain many small price changes. Table 3 , lines 1 through 3 , shows that more than half of non-sale price changes are smaller than 5 percent in absolute value, 26.1 percent are smaller than 2.5 percent, and 6.7 percent are smaller than 1 percent. These facts typically pose a challenge for menu cost models to match, since a menu cost large enough to prevent too-frequent price adjustments also prevents the firm from making many very small price changes. This problem is shared by the estimated menu cost model considered in this paper: in column (b), there are too few small price changes compared with the empirical data. Midrigan (forthcoming) and Dotsey et al. (1999) assume heterogeneity in menu costs, which is helpful in generating small price changes-in cases when the firm faces a small menu cost—alongside larger price changes as well.

The model with price points does not have as much trouble generating small price changes, as shown in columns (c) and (d). The model nearly matches the empirical data for nonsale price changes smaller than 2.5 percent and 1 percent in absolute value. While the model in column (e) matches the percentage of price changes smaller than 5 percent in absolute value, it 
fails to generate a reasonable number of very small changes. Intuitively, this shortcoming is similar to the shortcoming of most menu cost models: the large estimated $\kappa$ prevents many small price adjustments, as prices bounce too heavily between nine-ending levels.

Section I documented that the frequency of price changes in the Dominick's data varies depending on the previous period's price ending (lines 4 through 6 in Table 3). Columns (b) through (e) provide these moments using the estimated parameters. While the frequency of all price changes was not used in the estimations, the models produce frequencies comparable to but slightly less than the empirical data. ${ }^{13}$ More importantly, in the empirical data the frequency of price change is higher conditional on non-nine-ending prices than it is conditional on nineending prices. Such a pattern is qualitatively present in all the models that allow a role for price points. Quantitatively, column (e) — which was estimated without explicitly including a nineending moment — comes reasonably close to matching the data.

Section I also documented that the frequency with which post-sale prices differ from their pre-sale level varies with the pre-sale price ending (lines 7 through 9 of Table 3). Such a pattern is generated endogenously by the model if one allows for a nine-ending price point effect. Once again, column (e) comes closest to quantitatively matching the patterns in the Dominick's data, suggesting that the nine-ending effect may be toward the higher end of the estimates provided. Taken together, these facts and the above results provide strong evidence that price points play an important role in the memory prices exhibit around sales.

\footnotetext{
${ }^{13}$ The Dominick's data contain sale-to-sale changes that were ruled out for the sake of tractability in the model in Section III; this explains most of the discrepancy between the models and the data.
} 
V. Discussion

Developing models in which prices return to their pre-sale levels has proven challenging. In one approach, Kehoe and Midrigan (2008) present a stylized model featuring multiple menu costs: a large menu cost for non-sale price changes, a smaller menu cost for price changes associated with the start of a sale, and a de facto zero menu cost to change from the sale price back to the regular price. ${ }^{14}$ Because of the latter zero menu cost, this framework generates many prices that return exactly to their pre-sale levels. However, it contradicts the notion of a menu cost as the literal cost of implementing a price change; why should it be completely costless a priori to physically adjust some prices but not others? Further, it is not clear a priori that the physical costs of implementing a price change associated with a sale are lower than those associated with making a non-sale price change, especially if the former involves special tags, signs, etc. For these reasons, this paper posits a single menu cost.

In a second approach, Eichenbaum et al. (forthcoming) present a model in which a firm chooses a "price plan," which consists of a set of two prices. Firms can change between prices in the plan costlessly, but altering the plan requires paying a fixed cost. Intuitively, limiting the number of prices in the plan to two - for instance, to one regular and one sale price - and requiring a cost to changing the plan prevents firms from making the types of small adjustments seen in Figure 4 that plague menu cost models around sales. However, it is less clear why a profit-maximizing firm would select a plan with only two prices; specifically, when facing drift in the price level, the firm would optimally wish to have a cluster of "regular" prices to choose from, along with at least one sale price. The nine-ending price point model in this paper can

\footnotetext{
${ }^{14}$ Kehoe and Midrigan (2008) focus on "regular" and "temporary" price changes, where the latter include both sales and temporary price increases above the regular level. For comparison with this paper, I reframe the issue in terms of only sales.
} 
explain why firms might endogenously choose to use relatively few prices. ${ }^{15}$ In addition, the trivial size of the estimated menu costs is not too far from the assumption in Eichenbaum et al. (forthcoming) of costless price changes within a plan.

Clearly, price changes per se are not costless. Levy et al. (1997) provide direct evidence from time-use studies on the costs of changing prices for supermarkets: cumulatively, they average more than $\$ 100,000$ per year per store, or about 0.70 percent of firm revenues. The results above suggest that the estimated nine-ending price point effect is roughly two orders of magnitude larger than the cost associated with a single price change. Another way to compare these estimates is to combine them with the actual Dominick's pricing data across stores, items, and time to form the ratio:

$$
\frac{\sum_{s=\text { stores }} \sum_{i=\text { items }} \sum_{t=\text { time }} \hat{\kappa}\left[I\left(p_{s, i, t} \in\{9 \text {-ending price points }\}\right)\right]}{\sum_{s=\text { stores }} \sum_{i=\text { items }} \sum_{t=\text { time }} \hat{\Phi}\left[D_{s, i, t}\right]}, \quad D_{s, i, t}=\left\{\begin{array}{l}
1 \text { if } p_{s, i, t} \neq p_{s, i, t-1} \\
0 \text { otherwise }
\end{array}\right.
$$

Line 10 of Table 3 shows that these ratios vary, based on the parameter estimates, from 852.8 to 4225.0. If we assume that Dominick's is similar to the supermarket chains in the study by Levy et al. (1997) and pays 0.70 percent of revenues in the form of menu costs on average each year, these ratios would imply that Dominick's received a benefit from setting nine-ending prices in the range of 600 percent to 3000 percent of total revenues on average per year!

\footnotetext{
${ }^{15}$ Limiting the set of prices to those between $\$ 0.50$ and \$3.00 may increase the estimated importance of nine-ending prices if these are used to a greater extent for lower prices, or if they are a bigger factor in effecting price rigidity at lower levels simply because - in percentage terms - the distance between consecutive nine-ending prices is a decreasing function of the price level itself. However, price changes tend to be large in percentage terms (greater than $15 \%$ across all price changes), so above $\$ 0.69$ the distance between any two consecutive nine-ending prices is smaller than the average price change, suggesting this is not likely a binding constraint. In addition, firms may actually be more apt to focus on nine-ending prices at higher price levels, especially if they are used to simplify firms' pricing decisions (i.e., by limiting the realm of possible prices to one-tenth of the feasible pricing set). This latter point appears to be most likely: between $\$ 0.50$ and $\$ 3.00,62.2 \%$ of prices end in the digit nine, whereas $63.6 \%$ of all prices use this digit, signifying that they are more heavily used outside of the range of prices that are the focus of this study.
} 
These numbers are implausibly large. An alternative interpretation of the evidence is that Dominick's views menu costs differently from the standard menu cost set-up outlined above. Two previously modeled possibilities include economies of scale in changing prices (Midrigan forthcoming) and time variation in menu costs (Dotsey et al. 1999). But Dominick's may also simply view menu costs as a fixed cost of doing business rather than an impediment to price changes, as they are modeled in state-dependent pricing frameworks.

This paper's finding that menu costs are largely irrelevant as a source of price rigidity per se is in keeping with several recent lines of research that have looked to other explanations for sticky prices. In a case study of a large industrial manufacturer, Zbaracki et al. (2004) document that physical menu costs associated with changing prices were an order of magnitude smaller than the costs associated with collecting information and negotiating with customers. Blinder et al. (1998, p. 179) document that 15 of the 17 retailers in their survey identified price points as a significant source of price rigidity; by contrast, menu costs were cited by a below-average proportion of these same firms (p. 233). Overall in the Blinder et al. (1998) survey, the fear of antagonizing customers ranked very high as a primary reason behind firms' desires to keep their prices unchanged. Anderson and Simester (2010) and Rotemberg $(2005,2008)$ consider customer antagonization, anger, and perceptions of fairness over firms' prices as mechanisms that can generate price rigidity, even in the absence of menu costs. Related to antagonization, Knotek (2008, forthcoming) shows that under certain circumstances firms may choose to set convenient prices, which simplify and expedite transactions and result in price rigidity in a manner similar to price points. 
VI. Aggregate Implications

Deriving a structural explanation for price points and embedding this within a general equilibrium framework to generate macroeconomic dynamics is beyond the scope of this paper. As an approximation to the aggregate implications arising from the model with price points and menu costs, I consider the following exercise.

I assume the quantity equation with unit velocity holds, $M_{t}=P_{t} \times Y_{t}$. Money follows the dynamics previously assumed for the "price" component of nominal marginal cost, equation (5),

$$
\ln M_{t}=\bar{\pi}+\ln M_{t-1}+\zeta_{t}, \zeta_{t} \sim \text { i.i.d. } \mathrm{N}\left(0, \sigma_{\zeta}^{2}\right)
$$

with $\bar{\pi}$ and $\sigma_{\zeta}$ as in Section III. Individual prices aggregate to the price index $P_{t}$ via

(11) $\ln P_{t}=\frac{1}{N} \sum_{i=1}^{N} \ln p_{i t}$.

The model in Section III assumed nominal marginal cost for a good was $m c_{t}=P_{t} \times c_{t}$, where $P_{t}$ was the "price" component and $c_{t}$ was the "real" component of marginal cost. If monetary shocks are neutral, then $Y_{t}=\bar{Y}$ and recasting nominal marginal cost as $m c_{t}=M_{t} \times c_{t}$ differs from its earlier incarnation by a constant factor, which I omit to focus on dynamics. Under this conjecture, an individual price setter's problem is not affected by the decisions of other price setters. If monetary shocks are not neutral, however, then a price setter would more accurately need to take aggregate dynamics into account when making decisions; i.e., movements in output would enter marginal cost.

To compare and contrast the behavior of the typical menu cost model with the model with price points and menu costs, I simulate and aggregate a panel of one million price setters. Both models use the parameter estimates from Section IV and are simulated under the conjecture 
that monetary shocks are neutral, in keeping with the partial equilibrium model above. Figure 5 illustrates the simulated path of output deviations from trend over 200 weeks, using the same money process across models. ${ }^{16,17}$

The figure shows that output in the model with price points and menu costs is very nearly equal to its trend value throughout the simulation: the largest absolute deviation is 0.008 percent. That is, the model ex post largely confirms the ex ante conjecture that money is neutral. This result echoes Caplin and Spulber (1987), wherein price rigidity at the individual level is washed away in the aggregate.

By contrast, the typical menu cost model produces considerable movements in output related to changes in money: the largest absolute deviation is 0.684 percent. ${ }^{18}$ This result has two implications. First, the aggregate dynamics of the price point model appear to be quite distinct from those of the menu cost model. As such, the choice of a mechanism for generating price rigidity matters. However, the second point is that assuming ex ante monetary neutrality is more problematic in the menu cost case, since price setters would need to incorporate movements in $Y_{t}$ into marginal cost in their price-setting problem. Thus, a more detailed comparison of these two competing models requires a complete general equilibrium framework.

\footnotetext{
${ }^{16}$ Because of the different parameter estimates for the arrival rate and size of idiosyncratic real marginal cost shocks, and the frequency and size of sales shocks, the same cannot be said for all the shocks hitting individual price setters.

${ }^{17}$ While imposing the same money process across the two models is necessary for comparing aggregate responses, it generates one difference from the estimations in Section IV. The estimations constrain all movements and actions to the grid of relevant discretized state variables $-p / m c$ in 0.1 percent intervals in the standard menu cost model, and $p$ and $m c$ in one cent increments in the price point model. To allow for comparisons with the exact same money process between both models in this exercise, I simulate equation (10) directly and store $M$ for both models; then simulate $c$ directly for each price setter via equation (5) and the estimated values of $\lambda$ and $\theta$ for each model separately; then use these simulated values for nominal marginal cost $m c$ to find the nearest relevant discretized state variable, which is used in the price setter's decision problem.

${ }^{18}$ The standard deviation of output deviations from trend is 0.002 percent in the price point model and 0.208 percent in the typical menu cost model.
} 


\section{Conclusion}

This paper considers the extent to which menu costs - interpreted literally as the physical costs of changing a price - provide a structural explanation for price rigidity. Using scanner data from Dominick's Finer Foods, I show that in a simple menu cost model one would estimate a statistically and economically significant menu cost based on moments commonly used in the sticky price literature. By expanding the model to allow a role for price points and using additional empirical data in the estimation, the results change dramatically. In this case, the price point model can match the additional empirical facts, but menu costs are now effectively irrelevant as a source of price rigidity. These results suggest that treating menu costs as a structural explanation for sticky prices may be spurious.

This paper has made a number of simplifying assumptions for the sake of estimation feasibility. Most notably, in this paper prices that end in the digit nine raise the level of profits, while all other prices do not have any special effects. This tractable approach only adds one additional parameter to the estimation, but the exact manner in which price points enter the firm's problem is a subject of contention. While the marketing and retailing literatures have suggested many alternative theories to explain the prevalence of price points, further work is necessary to justify a structural interpretation of how they affect firms' decision-making and therefore produce price rigidity. Embedding this structural framework into a fully dynamic, stochastic general equilibrium model is left for future research. 
VIII. Appendix: The Sales Filter

For the sake of compatibility and comparability between the Dominick's data and the simulated price data, I construct a sales filter that is applied to both sets of data. In any given period, the filter determines whether a price observation is a sale or not by comparing the current price with an inferred "regular" price for the item. In short, if the price today has fallen below the "regular" price and increases within the next $F$ periods, then it is a sale price; otherwise, it is not a sale price. The window size, $F$, is set to four weeks in this paper; moments computed using a window size of three or five weeks are only slightly affected.

More formally, the following steps were used for a given item $i$.

1. Initially set "regular" prices $\left\{r_{t}\right\}$ to their observed values $\left\{p_{t}\right\}$ for all $t$.

2. Compare the current price with the previous period's regular price: if $p_{t} \geq r_{t-1}$, the observation is not a sale, move to the next period; if $p_{t}<r_{t-1}$, then continue to step 3 .

3. Over the next $F$ periods, does the price increase? If so, then time $t$ was part of a sale and the previous "regular" price needs to be carried forward to this period $\left(r_{t}=r_{t-1}\right)$; if not, there was not a sale at time $t$.

4. Move to the next period $(t=t+1)$ and return to step 2 .

Note that the "regular" prices are only used in the sales filter; none of the moments presented in the paper rely on these "regular" prices per se.

\section{References}

Anderson, Eric T., and Duncan Simester (2010) "Price Stickiness and Customer Antagonism" Quarterly Journal of Economics 125(2): 729-65. 
Blinder, Alan S., Elie R.D. Canetti, David E. Lebow, and Jeremy B. Rudd (1998) Asking About Prices: A New Approach to Understanding Price Stickiness Russell Sage Foundation: New York.

Brenner, Gabrielle A. and Reuven Brenner (1982) "Memory and Markets, or Why Are You Paying \$2.99 for a Widget?” Journal of Business 55(1): 147-58.

Caplin, Andrew S. and Daniel F. Spulber (1987) "Menu Costs and the Neutrality of Money" Quarterly Journal of Economics 102(4): 703-25.

Dhyne, Emmanuel, Luis J. Álvarez, Hervé Le Behan, Giovanni Veronese, Daniel Dias, Johannes Hoffman, Nicole Jonker, Patrick Lünnemann, Fabio Rumler, and Jouko Vilmunen (2006) "Price Changes in the Euro Area and the United States: Some Facts from Individual Consumer Price Data" Journal of Economic Perspectives 20(2): 171-92.

Dotsey, Michael, Robert G. King, and Alexander L. Wolman (1999) "State-Dependent Pricing and the General Equilibrium Dynamics of Money and Output" Quarterly Journal of Economics 114(2): 655-90.

Dutta, Shantanu, Mark Bergen, Daniel Levy, and Robert Venable (1999) "Menu Costs, Posted Prices, and Multiproduct Retailers" Journal of Money, Credit, and Banking 31(4): 683-703.

Eichenbaum, Martin, Nir Jaimovich, and Sergio Rebelo (forthcoming) "Reference Prices, Costs and Nominal Rigidities" American Economic Review.

Georgoff, David M. (1970) The Effects of Odd-Even Retail Pricing on Value Determination, Product Perception, and Buying Propensities East Lansing, MI: Michigan State University.

Gertler, Mark and John Leahy (2008) “A Phillips Curve with an Ss Foundation” Journal of Political Economy 116(3): 533-72.

Golosov, Mikhail and Robert E. Lucas, Jr. (2007) "Menu Costs and Phillips Curves” Journal of Political Economy 115(2): 171-99.

Kashyap, Anil K. (1995) "Sticky Prices: New Evidence from Retail Catalogs" Quarterly Journal of Economics 110(1): 245-74.

Kehoe, Patrick J. and Virgiliu Midrigan (2008) "Temporary Price Changes and the Real Effects of Monetary Policy" working paper.

Klenow, Peter J. and Oleksiy Kryvtsov (2008) "State-Dependent or Time-Dependent Pricing: Does It Matter for Recent U.S. Inflation?” Quarterly Journal of Economics 123(3): 863-904.

Knotek, Edward S., II (forthcoming) "Convenient Prices and Price Rigidity: Cross-Sectional Evidence" Review of Economics and Statistics. 
Knotek, Edward S., II (2008) "Convenient Prices, Currency, and Nominal Rigidity: Theory with Evidence from Newspaper Prices” Journal of Monetary Economics 55(7): 1303-16.

Levy, Daniel, Dongwon Lee, Haipeng Chen, Robert J. Kauffman, and Mark Bergen (forthcoming) "Price Points and Price Rigidity" Review of Economics and Statistics.

Levy, Daniel, Mark Bergen, Shantanu Dutta, and Robert Venable (1997) "The Magnitude of Menu Costs: Direct Evidence from Large U.S. Supermarket Chains” Quarterly Journal of Economics 112(3): 791-825.

Midrigan, Virgiliu (forthcoming) "Menu Costs, Multi-Product Firms, and Aggregate Fluctuations" Econometrica.

Nakamura, Emi and Jón Steinsson (2008) "Five Facts about Prices: A Reevaluation of Menu Cost Models" Quarterly Journal of Economics 123(4): 1415-64.

Peltzman, Sam (2000) "Prices Rise Faster than They Fall” Journal of Political Economy 108(3): 466-502.

Rotemberg, Julio J. (2005) "Customer Anger at Price Increases, Changes in the Frequency of Price Adjustment, and Monetary Policy” Journal of Monetary Economics 52(4): 829-52.

Rotemberg, Julio J. (2008) "Fair Pricing” working paper.

Schindler, Robert M. (1991) "Symbolic Meanings of a Price Ending” Advances in Consumer Research 18(1): 794-801.

Schindler, Robert M. and Patrick N. Kirby (1997) "Patterns of Rightmost Digits Used in Advertised Prices: Implications for Nine-Ending Effects" Journal of Consumer Research 24(2): 192-201.

Thomas, Manoj and Vicki Morwitz (2005) "Penny Wise and Pound Foolish: The Left-Digit Effect in Price Cognition” Journal of Consumer Research 32(1): 54-64.

Zbaracki, Mark J., Mark Ritson, Daniel Levy, Shantanu Dutta, and Mark Bergen (2004) "Managerial and Customer Costs of Price Adjustment: Direct Evidence from Industrial Markets" Review of Economics and Statistics 86(2): 514-33. 
Table 1: Parameter Estimates and Moments

\begin{tabular}{|c|c|c|c|c|c|}
\hline & $\begin{array}{c}\text { (a) } \\
\text { Dominick's } \\
\text { data }\end{array}$ & $\begin{array}{c}\text { (b) } \\
\text { Typical menu } \\
\text { cost model }\end{array}$ & $\begin{array}{l}\text { (c) } \\
\text { Model with price } \\
\text { points and menu } \\
\text { costs }\end{array}$ & $\begin{array}{l}\text { (d) } \\
\text { Excluding the pre- } \\
\text { v. post-sales } \\
\text { moment }\end{array}$ & $\begin{array}{c}(\mathrm{e}) \\
\text { Excluding the } \\
\text { "nines" moment }\end{array}$ \\
\hline \multicolumn{6}{|l|}{ Estimates } \\
\hline Nine-ending price point effect: $\kappa$ & & - & $\begin{array}{c}5.30 \times 10^{-4} \\
{[5.19,5.65] \times 10^{-4}}\end{array}$ & $\begin{array}{c}5.30 \times 10^{-4} \\
{[5.17 .5 .65] \times 10^{-4}}\end{array}$ & $\begin{array}{c}1.77 \times 10^{-3} \\
{[1.78,2.25] \times 10^{-3}}\end{array}$ \\
\hline Menu cost: $\Phi$ & & $\begin{array}{c}2.51 \times 10^{-3} \\
{[2.18,2.91] \times 10^{-3}}\end{array}$ & $\begin{array}{c}1.78 \times 10^{-6} \\
{[0.35,11.2] \times 10^{-6}}\end{array}$ & $\begin{array}{c}1.18 \times 10^{-6} \\
{[0.23,17.8] \times 10^{-6}}\end{array}$ & $\begin{array}{c}1.20 \times 10^{-6} \\
{[0.83,51.7] \times 10^{-6}}\end{array}$ \\
\hline Arrival probability of cost shocks: $\lambda$ & & $\begin{array}{c}0.059 \\
{[0.058,0.062]}\end{array}$ & $\begin{array}{c}0.022 \\
{[0.021,0.025]}\end{array}$ & $\begin{array}{c}0.022 \\
{[0.020,0.028]}\end{array}$ & $\begin{array}{c}0.157 \\
{[0.150,0.173]}\end{array}$ \\
\hline Absolute bound on cost shocks: $\theta$ & & $\begin{array}{c}0.098 \\
{[0.095,0.101]}\end{array}$ & $\begin{array}{c}0.083 \\
{[0.069,0.098]}\end{array}$ & $\begin{array}{c}0.090 \\
{[0.065,0.096]}\end{array}$ & $\begin{array}{c}0.020 \\
{[0.019,0.022]}\end{array}$ \\
\hline No sale to no sale transition probability: $\delta_{0}$ & & $\begin{array}{c}0.895 \\
{[0.893,0.896]}\end{array}$ & $\begin{array}{c}0.875 \\
{[0.867,0.878]}\end{array}$ & $\begin{array}{c}0.875 \\
{[0.868,0.879]}\end{array}$ & $\begin{array}{c}0.878 \\
{[0.874,0.887]}\end{array}$ \\
\hline Small sale to no sale transition probability: $\delta_{s}$ & & $\begin{array}{c}0.329 \\
{[0.316,0.341]}\end{array}$ & $\begin{array}{c}0.399 \\
{[0.394,0.410]}\end{array}$ & $\begin{array}{c}0.399 \\
{[0.390,0.411]}\end{array}$ & $\begin{array}{c}0.412 \\
{[0.407,0.423]}\end{array}$ \\
\hline Size of big sale: $\xi_{b}$ & & $\begin{array}{c}0.521 \\
{[0.517,0.522]}\end{array}$ & $\begin{array}{c}0.517 \\
{[0.501,0.525]}\end{array}$ & $\begin{array}{c}0.517 \\
{[0.505,0.527]}\end{array}$ & $\begin{array}{c}0.526 \\
{[0.517,0.541]}\end{array}$ \\
\hline Size of small sale: $\xi_{s}$ & & $\begin{array}{c}0.102 \\
{[0.097,0.103]}\end{array}$ & $\begin{array}{c}0.106 \\
{[0.102,0.110]}\end{array}$ & $\begin{array}{c}0.106 \\
{[0.102,0.110]}\end{array}$ & $\begin{array}{c}0.114 \\
{[0.109,0.119]}\end{array}$ \\
\hline \multicolumn{6}{|l|}{ Moments } \\
\hline 1. Frequency of non-sale price changes & 0.06 & 0.06 & 0.06 & 0.06 & 0.06 \\
\hline 2. Avg. absolute size of non-sale price changes & 0.08 & 0.08 & 0.09 & 0.09 & 0.09 \\
\hline 3. St. dev. of size of non-sale price changes & 0.09 & 0.09 & 0.12 & 0.12 & 0.11 \\
\hline 4. Frequency of beginning a sale & 0.10 & 0.10 & 0.11 & 0.11 & 0.11 \\
\hline 5. Frequency of ending a sale & 0.51 & 0.51 & 0.54 & 0.54 & 0.54 \\
\hline 6. Avg. size of price changes at start of sales & -0.22 & -0.22 & -0.23 & -0.23 & -0.23 \\
\hline 7. St. dev. of size of price changes at start of sales & 0.19 & 0.19 & 0.19 & 0.19 & 0.19 \\
\hline 8. Percentage of all prices that end in 9 & 0.62 & 0.10 & 0.63 & 0.63 & 0.91 \\
\hline 9. Frequency of post-sale prices differing from pre-sale levels & 0.11 & 0.93 & 0.10 & 0.10 & 0.10 \\
\hline
\end{tabular}

Notes: Moments computed from the Dominick's data were for prices between $\$ 0.50$ and $\$ 3.00$ inclusive. The models were estimated using simulated method of moments. For the parameter estimates, 90-percent confidence intervals are reported in square brackets [-], as detailed in the text. For columns (b)-(e), the reported moments were computed based on the estimated parameters; moments shaded in gray were not used in the estimation. See Section II and Section III for details on the parameters. 
Table 2: Interpreting the Menu Cost $\Phi$ and the Nine-Ending Price Point Effect $\kappa$

\begin{tabular}{|c|c|c|c|c|}
\hline & $\begin{array}{l}\text { (b) } \\
\text { Typical menu } \\
\text { cost model }\end{array}$ & $\begin{array}{l}\text { (c) } \\
\text { Model with price } \\
\text { points and menu } \\
\text { costs }\end{array}$ & $\begin{array}{l}\text { (d) } \\
\text { Excluding the } \\
\text { pre- v. post-sales } \\
\text { moment }\end{array}$ & $\begin{array}{l}\text { (e) } \\
\text { Excluding the } \\
\text { "nines" moment }\end{array}$ \\
\hline $\begin{array}{l}\text { The percent deviation between the actual markup and } \\
\text { the steady-state desired markup comparable to: } \\
1 \text {. The estimated menu cost } \Phi \\
2 . \text { The estimated nine-ending price point effect } \kappa\end{array}$ & $\begin{array}{c}3.46 \% \\
-\end{array}$ & $\begin{array}{l}0.09 \% \\
1.60 \%\end{array}$ & $\begin{array}{l}0.08 \% \\
1.60 \%\end{array}$ & $\begin{array}{l}0.08 \% \\
2.91 \%\end{array}$ \\
\hline
\end{tabular}


Table 3: Additional Moments of Interest

\begin{tabular}{|c|c|c|c|c|c|}
\hline & $\begin{array}{l}\text { (a) } \\
\text { Dominick's } \\
\text { data }\end{array}$ & $\begin{array}{l}\text { (b) } \\
\text { Typical menu } \\
\text { cost model }\end{array}$ & $\begin{array}{l}\text { (c) } \\
\text { Model with price } \\
\text { points and menu } \\
\text { costs }\end{array}$ & $\begin{array}{c}(\mathrm{d}) \\
\text { Excluding the } \\
\text { pre- v. post-sales } \\
\text { moment }\end{array}$ & $\begin{array}{c}\text { (e) } \\
\text { Excluding the } \\
\text { "nines" moment }\end{array}$ \\
\hline \multicolumn{6}{|l|}{ Small Price Changes } \\
\hline 1. Percentage of non-sale changes $<|5 \%|$ & 52.3 & 38.9 & 41.6 & 39.9 & 51.9 \\
\hline 2. Percentage of non-sale changes $<|2.5 \%|$ & 26.1 & 16.9 & 26.0 & 25.9 & 4.7 \\
\hline 3. Percentage of non-sale changes $<|1 \%|$ & 6.7 & 0.2 & 5.6 & 6.9 & 2.1 \\
\hline \multicolumn{6}{|l|}{ Frequency Measures } \\
\hline 4. Frequency of all price changes & 25.0 & 22.8 & 23.2 & 23.3 & 24.2 \\
\hline 5. Frequency | last price ended in 9 & 21.5 & - & 22.1 & 22.2 & 22.9 \\
\hline 6. Frequency | last price did not end in 9 & 30.5 & - & 25.4 & 25.4 & 38.0 \\
\hline \multicolumn{6}{|l|}{ Prices around Sales } \\
\hline 7. Frequency of post-sale prices differing from pre-sale levels & 11.0 & 93.2 & 9.7 & 9.7 & 10.4 \\
\hline 8. Frequency | last non-sale price ended in 9 & 6.1 & - & 8.1 & 8.2 & 9.1 \\
\hline 9. Frequency | last non-sale price did not end in 9 & 22.4 & - & 12.7 & 12.5 & 23.6 \\
\hline \multicolumn{6}{|l|}{$\underline{\text { Ratio }}$} \\
\hline 10. (Gains from nine endings)/(Menu costs paid) & - & - & 852.8 & 1286.4 & 4225.0 \\
\hline
\end{tabular}


Figure 1: The Distribution of Prices in the Dominick's Dataset

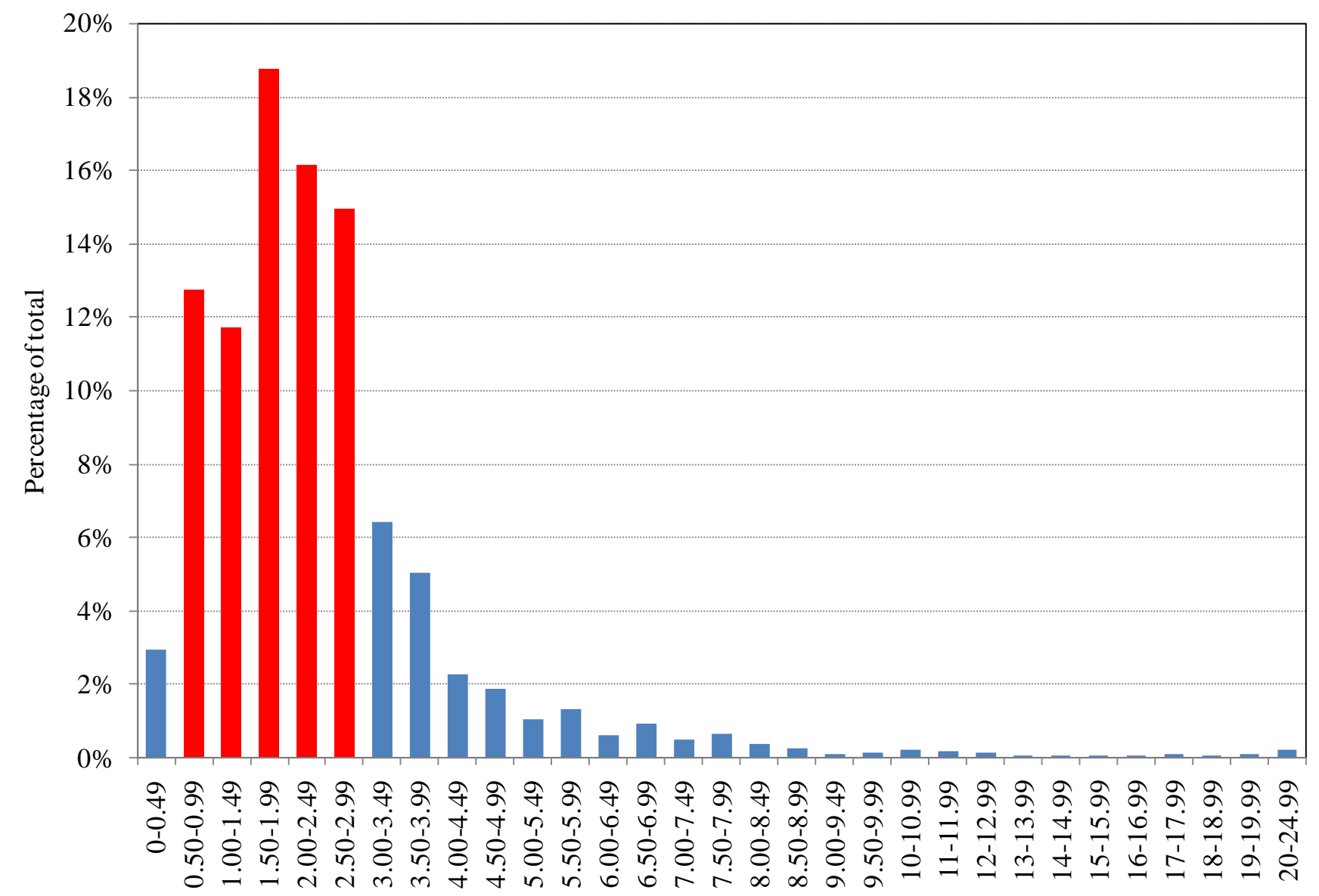

Bins, in dollars

Notes: Prices are from the Dominick's Finer Foods database. The red bars indicate the data used for this study. Less than $0.01 \%$ of prices in the Dominick's dataset are greater than $\$ 24.99$. 
Figure 2: The Distribution of Price Endings in the Dominick's Dataset

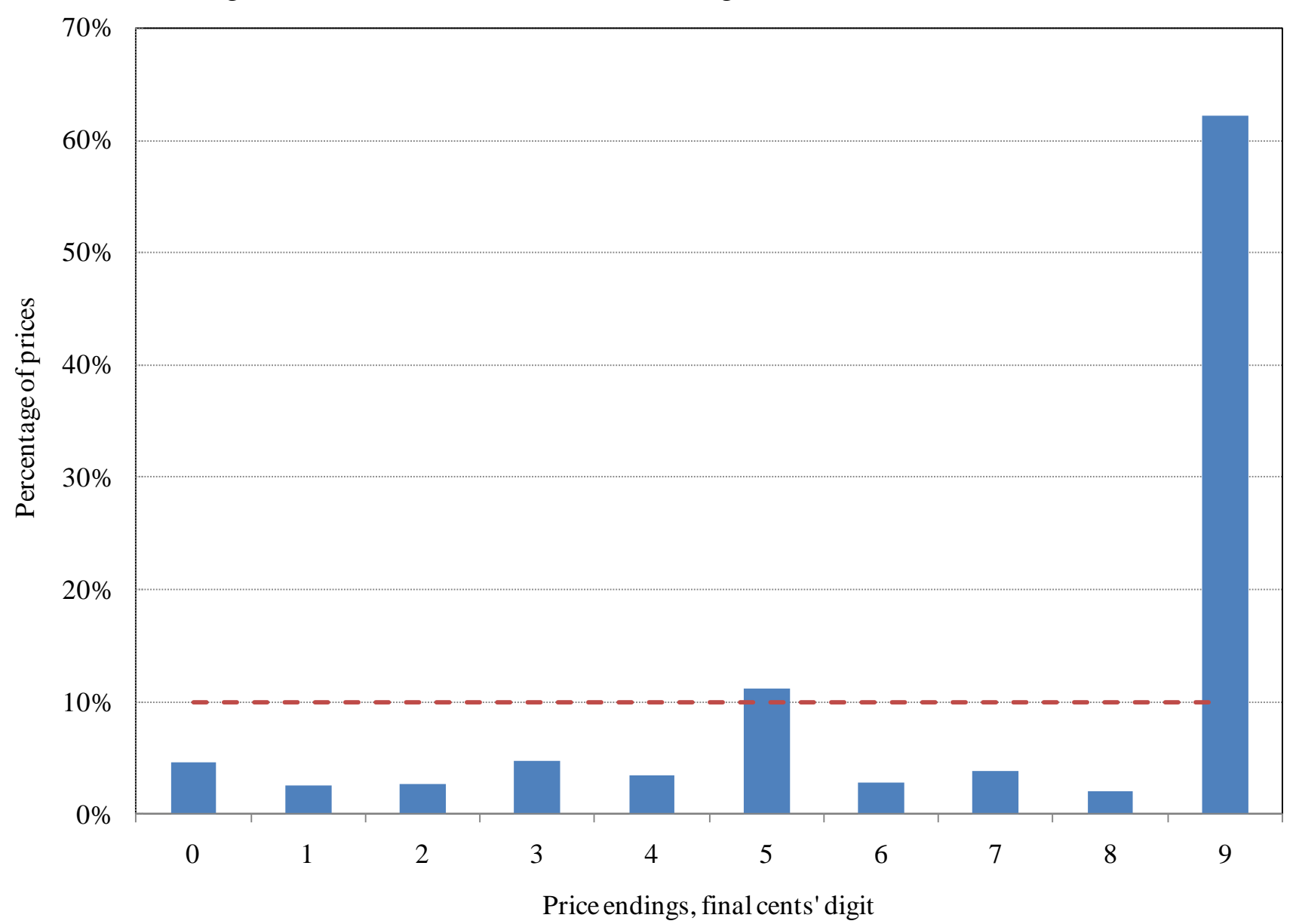

Notes: Prices are from the Dominick's Finer Foods database, for prices in the range of $\$ 0.50$ to $\$ 3.00$ inclusive. The red dashed line represents a uniform distribution of price endings. 
Figure 3: The Frequency of Post-Sale Prices Differing from Their Pre-Sale Levels

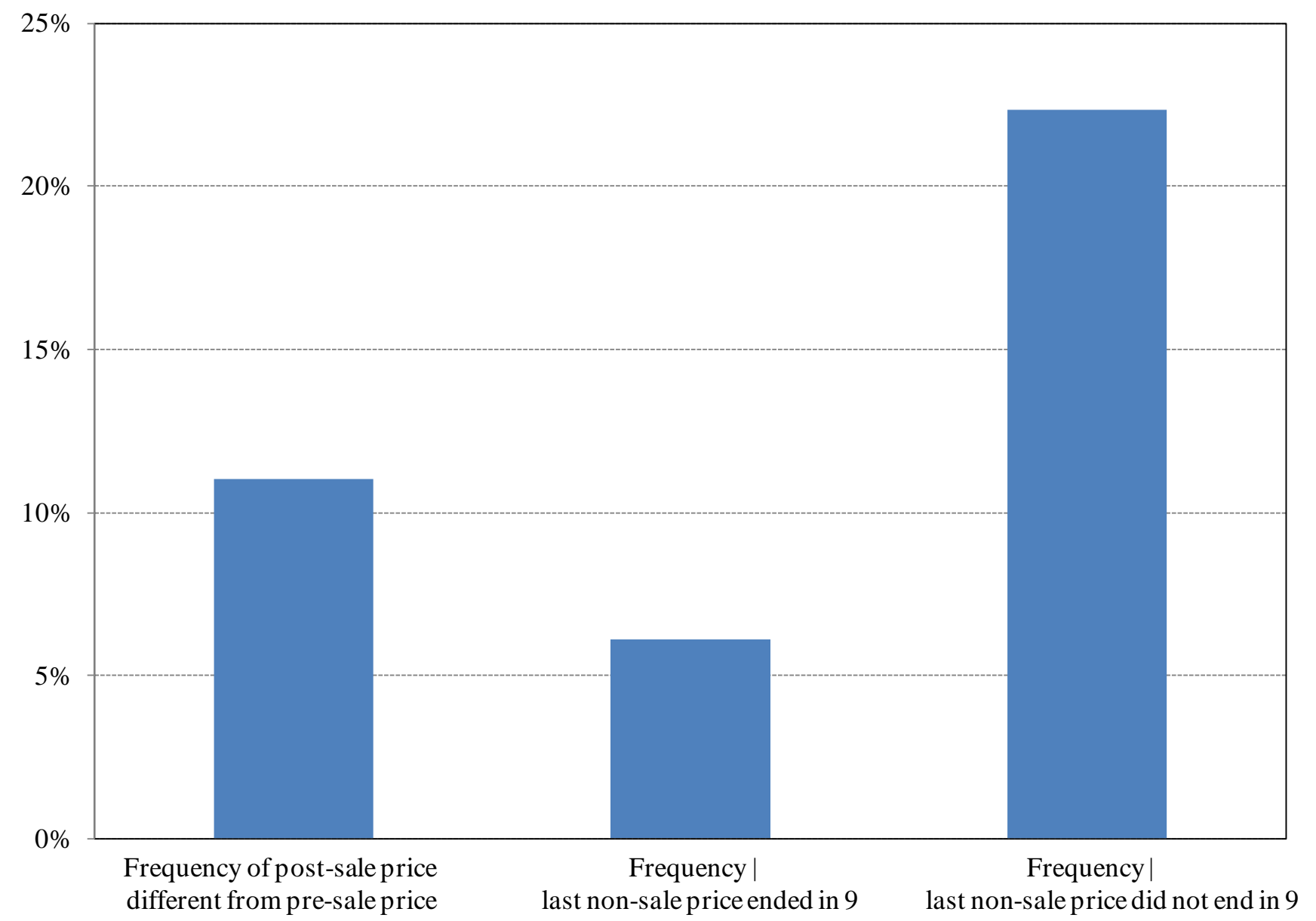


Figure 4: Sales and the Problem with Menu Cost Models

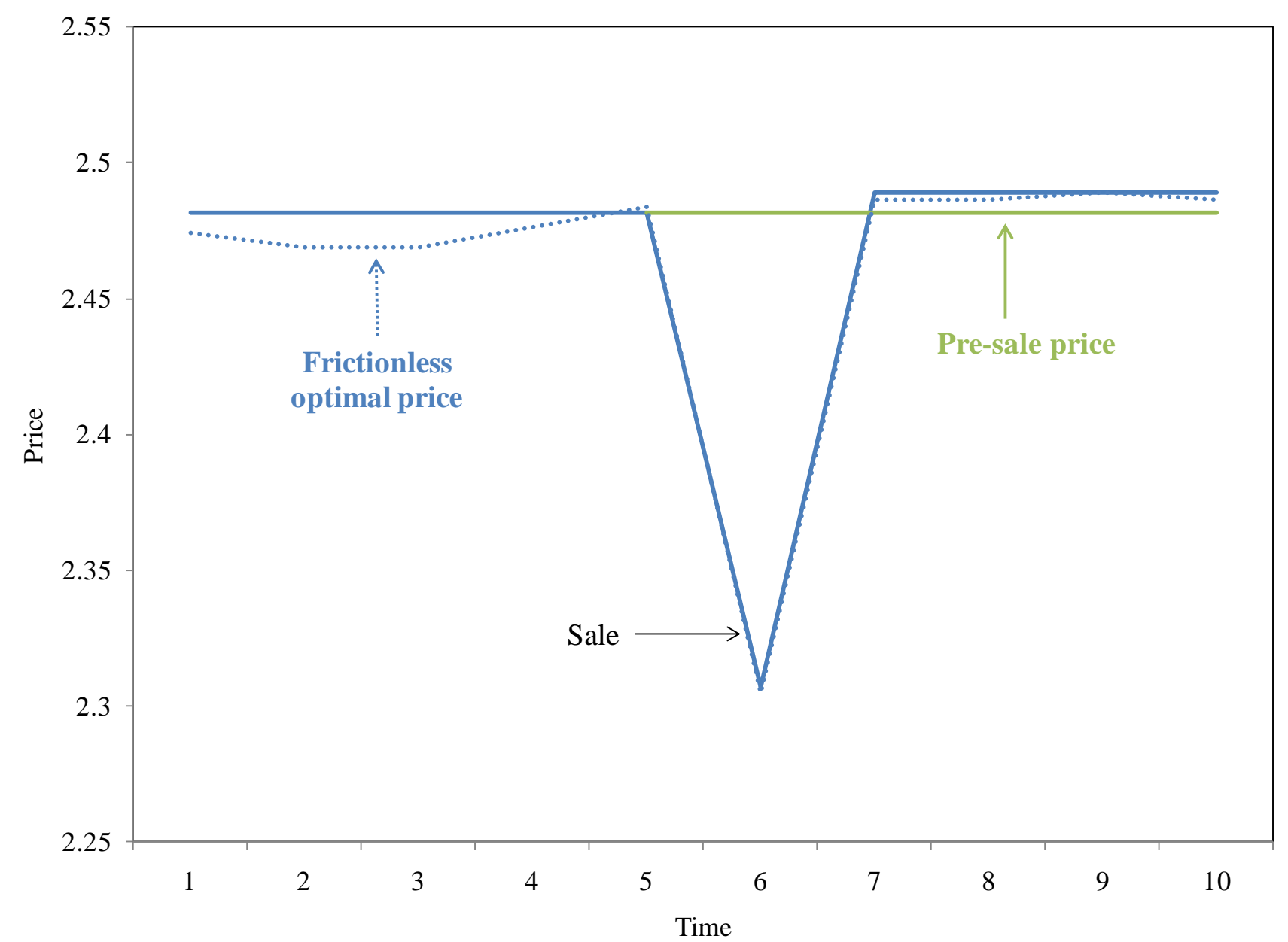

Note: The frictionless optimal price in each period is given by the product of the firm's nominal marginal costs $m c$ and the desired markup $\mu$. 
Figure 5: Simulated Output Deviations from Trend in Two Models

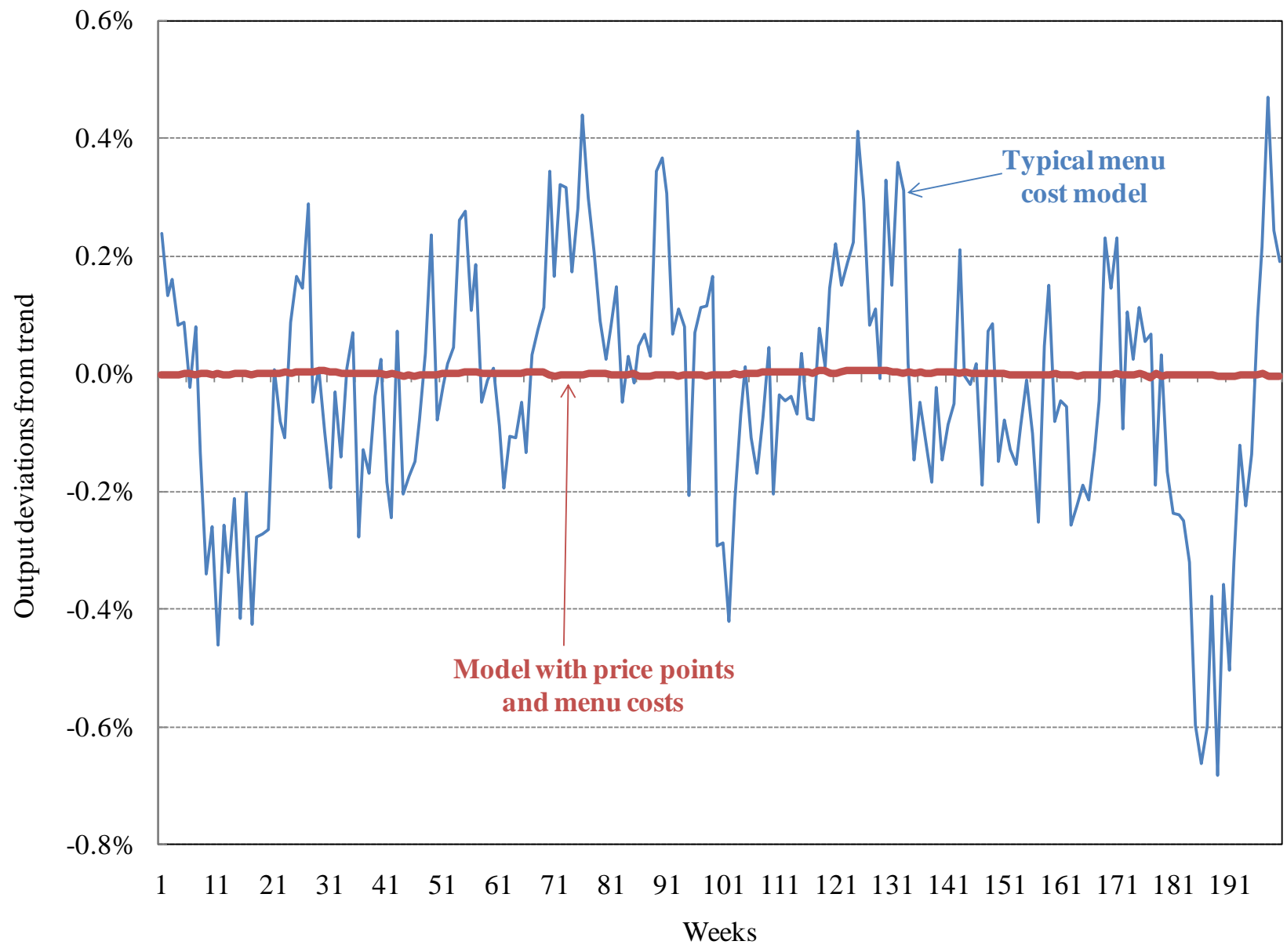

Notes: The thin blue line shows output deviations from trend for the typical menu cost model. The thick red line shows output deviations from trend for the model with price points and menu costs. Both models were simulated using the parameter estimates from Section IV. Both models assume ex ante that monetary shocks are neutral. 